Correction

\title{
Correction: Hyseni, C.; Garrick, R.C. Ecological Drivers of Species Distributions and Niche Overlap for Three Subterranean Termite Species in the Southern Appalachian Mountains, USA. Insects $2019,10,33$
}

\author{
Chaz Hyseni * ${ }^{-1}$ and Ryan C. Garrick \\ Department of Biology, University of Mississippi, University, MS 38677, USA; rgarrick@olemiss.edu \\ * Correspondence: chaz.hyseni@gmail.com
}

Received: 17 February 2020; Accepted: 20 February 2020; Published: 26 February 2020

It has recently come to our attention that two of the environmental rasters we used for analyses in our study [1] were mislabeled in a raster processing pipeline. As a result, in the article [1], all references to dry-season precipitation and summer temperature require switching. Here, Figures 1 and 2 and Table 1 , are the corrected versions of Figures 1 and 3 and Table 2 in the article [1].

In the abstract, one of the sentences should read: "Overall, we found that $R$. flavipes and $R$. virginicus showed significant niche divergence, which was primarily driven by summer temperature."

The first paragraph in the Results section should read: "Bimodality was also observed for summer temperature in $R$. flavipes, given that the species occurs in both low elevations and the cooler high-elevation areas of the Appalachians (see Figure S3). Statistics that characterize the extent of niche overlap showed that $R$. flavipes and $R$. virginicus had the least amount of overlap ( $\mathrm{D}=0.582, \mathrm{I}=0.843) . "$ In the same paragraph, a correction is required two sentences later: "R. malletei was more similar to $R$. flavipes in terms of temperature range $(D=0.889)$ and summer temperature $(D=0.872)$ but showed more overlap with $R$. virginicus for dry- $(\mathrm{D}=0.894)$ and wet-season precipitation $(\mathrm{D}=0.848) . "$

In the "Environmental Factors and Niche Divergence" subsection of the Results, all references to dry-season precipitation should actually be references to summer temperature. The last correction is in the Discussion section, in the last paragraph of the "Reticulitermes Distributions and Climatic Drivers of Niche Divergence among Species" subsection: "Furthermore, using distance-based redundancy analysis, we identified summer temperature as a major driver of this divergence."

The authors wish to apologize for the error and any inconvenience this may have caused. 

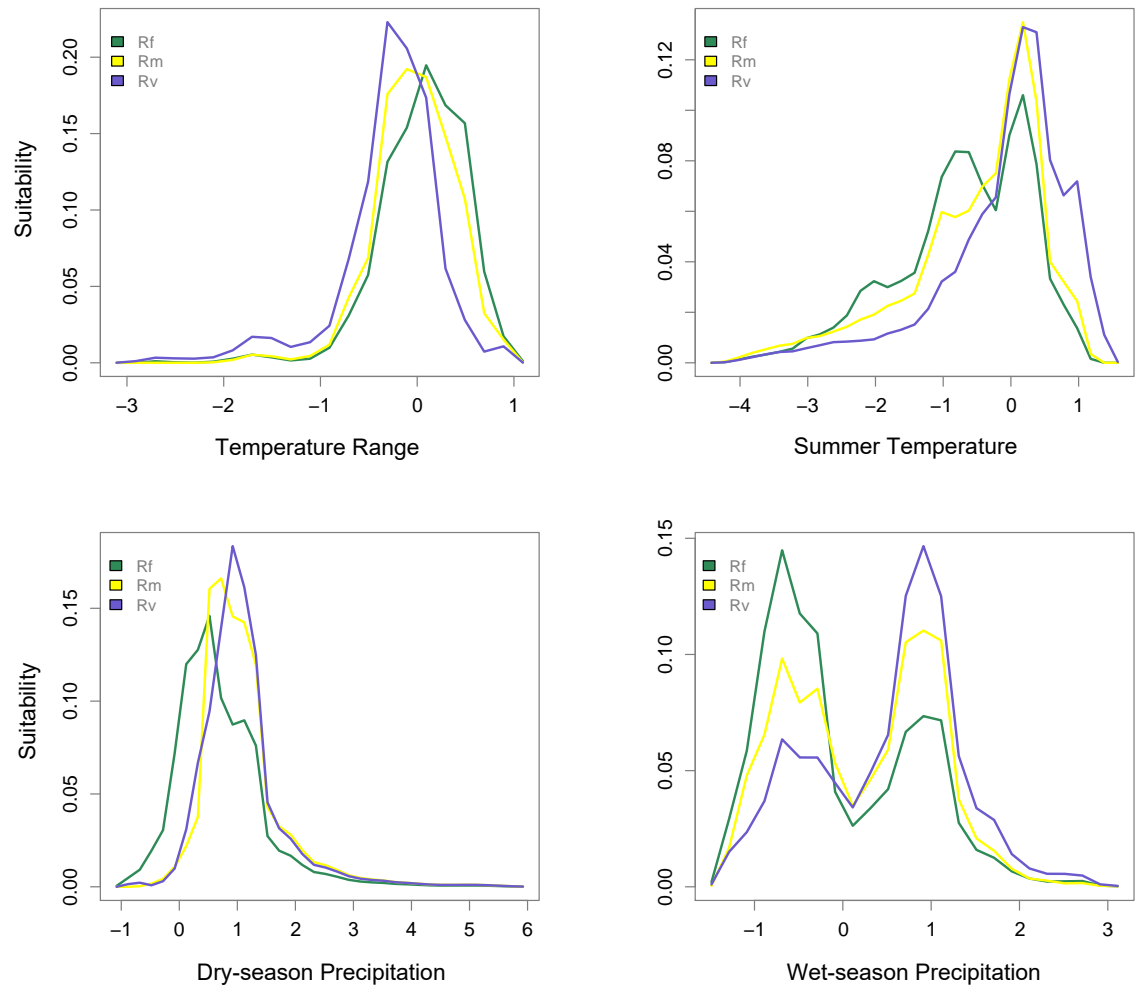

Figure 1. Predicted niche occupancy. Four environmental factors were used to estimate niche occupancy of $R$. flavipes (Rf), R. malletei (Rm), and R. virginicus (Rv): top two panels: temperature range and summer temperature; bottom two panels: dry- and wet-season precipitation. The y-axis represents niche occupancy, or suitability, and the area under the curves sums to 1 , the total suitability.

Table 1. Pairwise niche overlap among Reticulitermes species for each of four environmental factors. The top three rows show Schoener's D statistic, and the bottom three rows show the modified Hellinger statistic, I. The four environmental factors are: temperature range (TR), summer temperature (ST), dry-season precipitation (DP), and wet-season precipitation (WP). Niche overlap is highest in green and lowest in red. $R$. flavipes, $R$. malletei, and $R$. virginicus are abbreviated as $\mathrm{Rf}, \mathrm{Rm}$, and $\mathrm{Rv}$, respectively.

\begin{tabular}{cccccc}
\hline & & TR & ST & DP & WP \\
\hline \multirow{4}{*}{$D$} & $\mathrm{Rf} / \mathrm{Rm}$ & 0.889 & 0.872 & 0.693 & 0.820 \\
& $\mathrm{Rf} / \mathrm{Rv}$ & 0.683 & 0.707 & 0.680 & 0.680 \\
& $\mathrm{Rm} / \mathrm{Rv}$ & 0.791 & 0.809 & 0.894 & 0.848 \\
\hline \multirow{3}{*}{$\mathrm{I}$} & $\mathrm{Rf} / \mathrm{Rm}$ & 0.991 & 0.990 & 0.919 & 0.982 \\
& $\mathrm{Rf} / \mathrm{Rv}$ & 0.917 & 0.928 & 0.926 & 0.942 \\
& $\mathrm{Rm} / \mathrm{Rv}$ & 0.952 & 0.961 & 0.990 & 0.984 \\
\hline
\end{tabular}




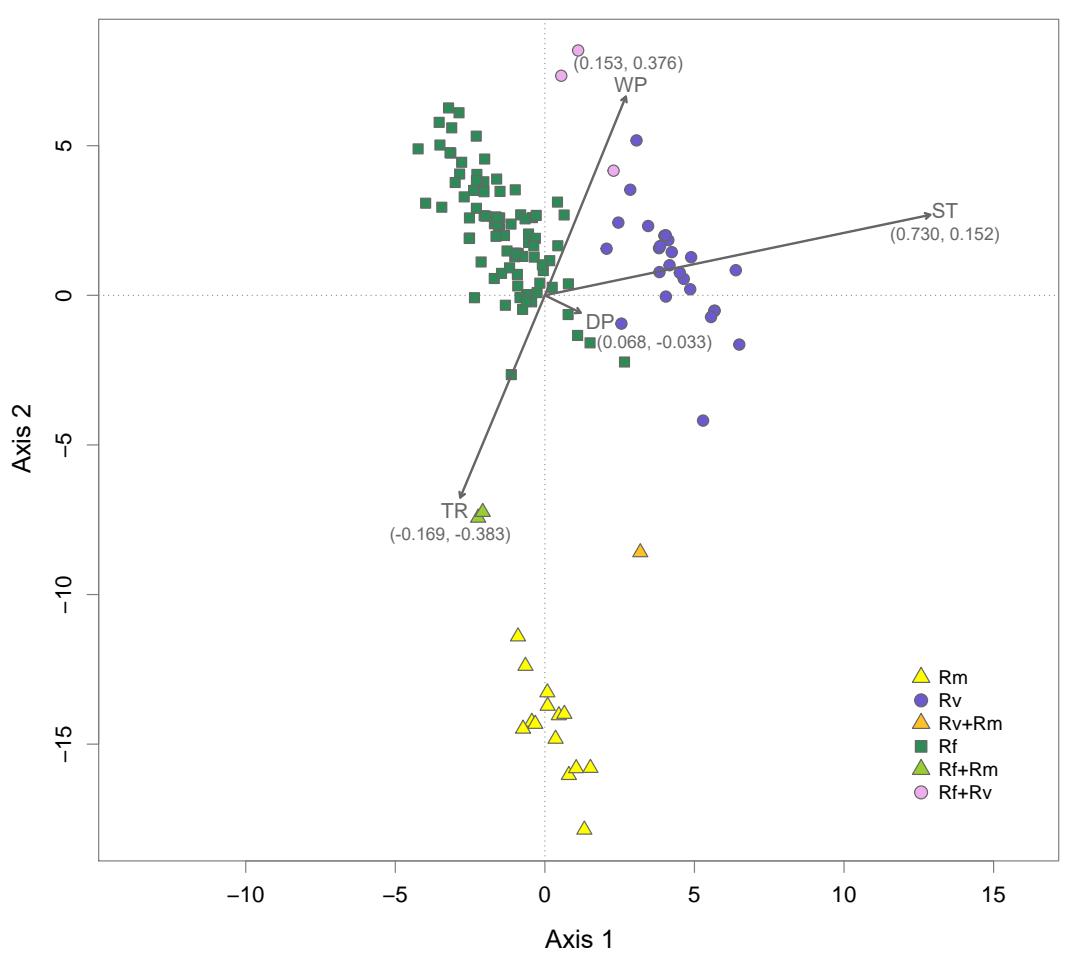

Figure 2. Distance-based redundancy analysis. The plot shows a constrained ordination of 132 sampling sites, color-coded based on the number of species present. Sites where only $R$. flavipes, $R$. virginicus, or $R$. malletei were sampled are referred to in the legend as "Rf", "Rv", and "Rm", respectively. Two-species sites are shown in the legend as " $\mathrm{Rf}+\mathrm{Rv}$ ", " $\mathrm{Rf}+\mathrm{Rm}$ ", and " $\mathrm{Rv}+\mathrm{Rm}$ ". The ordination is conditional on six significant spatial components (PCNM axes 1, 4, 6, 17, 43, and 58) and constrained by four environmental factors: dry-season precipitation (DP); wet-season precipitation (WP); summer temperature (ST); temperature range (TR). Arrows show strength of correlation (coefficients in parentheses) of environmental factors with ordination axes 1 and 2.

\section{References}

1. Hyseni, C.; Garrick, R.C. Ecological drivers of species distributions and niche overlap for three subterranean termite species in the southern Appalachian Mountains, USA. Insects 2019, 10, 33, doi:10.3390/insects10010033.

(C) 2020 by the authors. Licensee MDPI, Basel, Switzerland. This article is an open access article distributed under the terms and conditions of the Creative Commons Attribution (CC BY) license (http:/ / creativecommons.org/licenses/by/4.0/). 